\title{
EVALUATION OF CELERITY AND VELOCITY FOR TSUNAMI PROPGATION INTO RIVERS
}

\author{
Min Roh ${ }^{1}$, Hitoshi Tanaka ${ }^{1}$, Mohammad Bagus Aditaywan ${ }^{1}$, Akira Mano ${ }^{2}$ \\ and Keiko Udo ${ }^{2}$
}

\begin{abstract}
Tsunami propagation into rivers is one of the important real phenomena. During this process, the tsunami celerity and the flow velocity are significant physical parameters to understand tsunami behaviors. However, the availability of measurement data was not sufficient in case of the 2011 off the Pacific Coast of Tohoku Tsunami. Nevertheless, several video data can be used to assess the physical parameters such as tsunami celerity and flow velocity. In this study, as a video image analysis method, Particle Image Velocimetry(PIV) and Particle Tracking Velocimetry(PTV) were used to estimate the tsunami flow velocity. Furthermore, the analysis result of the video image data was verified by using the conservation equation. The tsunami physical parameter from PIV shows good comparison with other approaches.
\end{abstract}

Keywords: The 2011 off the Pacific Coast of Tohoku Tsunami; tsunami propagation; rivers; flow velocity; Particle Image Velocimetry(PIV); Particle Tracking Velocimetry(PTV)

\section{INTRODUCTION}

The off the Pacific Coast of Tohoku Earthquake occurred March 11, 2011. The earthquake generated a huge tsunami wave. Tohoku District of Japan was severely damaged by this tsunami event. The tsunami wave arrived at northeastern coast of Japan approximately 1-2 hours after the earthquake occurrence. Houses, building, infrastructures were destroyed due to the tsunami wave that was caused by the powerful earthquake. Tohoku District had suffered heavy causalities. Most of the urban area near the coastal line had been disappeared completely. Thus, the earthquake and the tsunami event have been recorded as one of the most devastating natural disaster in the world, historically. Currently, this tsunami issue is a major concern among the earthquake and tsunami researchers.

The tsunami wave propagation and inundation affected many changes of costal environment as well as river area. In the propagation process, it is found that tsunami wave propagated faster in rivers than on land. The tsunami wave in rivers arrived early at the river upstream area. The difference of tsunami impact on land and rivers can be seen clearly(Adityawan et al., 2012). The tsunami intrusion into rivers is also an important tsunami phenomenon that is closely related to secondary disaster such as the tsunami infiltration and overflow over the river embankment into an unexpected area in the upstream part of the river. In addition, the tsunami travel distance in rivers and on land has a big difference. These are some of the important features in understanding tsunami behaviors in rivers.

However, the tsunami intrusion into rivers received less attention than the study for tsunami inundation in coastal area and propagation model on the ocean. Nevertheless, some researchers continue to study and contribute on this topic. Abe(1986) analyzed observed rivers data of Japan Islands. The tsunami propagation features was explained by the water level data analysis. Furthermore, the tsunami wave in rivers has a similarity with the bore motion. The relationship between wave and river discharge was evaluated by laboratory experiment and numerical simulation.(Tsuji, 1991)

Recently, various numerical simulations and experiments have been carried out. Yasuda(2010) simulated the tsunami propagation into rivers by using one-dimension numerical model. The effect of 2004 tsunami were verified by using numerical model and field observation.(Wijetunge, 2009) Tanaka et al.(2008,2011) conducted the field survey that tsunami impact on Sri Lankan rivers due to 2004 Indian Ocean Tsunami. The effect of river basin scale was considered in that paper. According to the 2010 Chilean tsunami, it was found that river mouth morphology is one of the important factors by using tsunami height analysis when the tsunami propagated into rivers. Based on analysis result, the river classification was suggested according to the type and structures of river mouth. Thus, the past research results given valuable and useful information of tsunami propagation process. In the past research result, this tsunami behavior can be explained easily by tsunami physical parameters such as celerity and flow velocity. In order to achieve a detail investigation of tsunami effect into river, tsunami celerity and tsunami flow velocity will be very essential parameters.

\footnotetext{
${ }^{1}$ Dept. of Civil Eng., Tohoku University, 6-6-06 Aoba, Sendai, 980-8579, Japan

2 Disaster Control Research Center, Tohoku University, 6-6-11 Aoba, Sendai, 980-8579, Japan
} 
However, in the last tsunami event, data availability was limited because most measurement stations on the ocean and rivers were destroyed and washed away due to the massive tsunami wave. Data collection was never easy to get the stable data, and the most observed data has a low availability and quality. Fortunately, many video recorded during last tsunami event. Real phenomena for the tsunami propagation and inundation were contained in the collected video image data. In case, video image analysis can be used to analyze natural phenomena. It is useful and effective in such limited situation and low data availability, especially, Particle Image Velocimetry(PIV) that is commonly used to analyze the image data. PIV analysis method is being developed, and various techniques and methods for image analysis have been verified by many researchers. Fujita et al.(2001) and Holland et al.(2001) studied PIV measurement techniques in various flow condition such as river flood flow and so on. Hauet et al.(2008) and Kantoush et al.(2011) evaluated the availability and the sensitivity of PIV analysis method by using large scale laboratory experiments, and to improve its availability for real case. The analysis method required expensive measurement devices and large scale experiment laboratory. The image data were obtained from the stable camera angle like CCTV, and image data quality could be controlled. However, raw video data actually have many difficulties, especially moving and oblique camera viewpoint. Fritz et al.(2006) conducted PIV analysis for the raw video data of the Great Indian Tsunami 2004 in Banda Aceh. They proposed the tsunami flow velocity and Froude number. Unfortunately, it was not verified sufficiently about the conventional problems of raw video data. The verification of PIV method is crucial to allow this analysis method for further application in assessing tsunami behaviors based on collected videos of a tsunami event. Pre-process of the raw video image is required prior to improve the availability for PIV method application. The process has to overcome the problems such as camera body shaking, oblique camera view point, etc.

In this study, the verification of PIV is carried out by a comparison with theoretical approach and tracking debris analysis. It will provide a good comparison result and reliable physical parameter. The research result can help to understand the real phenomena of last tsunami event. Furthermore, the proposed image analysis process will be used practically to assess the tsunami flow velocity under the limited data and the estimation condition.

\section{STUDY AREA}

Figure 1 shows the location of study area. Study area is located in Sendai Plain. This area is close to Sendai City in Tohoku District. Sendai City is one of biggest cities in northeastern area of Japan. Therefore, there is shown that the population density is high and vital infrastructures such as Sendai Port, Sendai Airport, Highway, etc. are located in this place. It has several rivers that Sunaoshi River, Nanakita River, Natori River are located along the Sendai Coast. Thus, this area is actively studied by researchers, Japan government, and special organizations. Especially, the Sunaoshi River has available water level data and video image data. These data is an important role to perform video image analysis although the location of video recording and measurement station is a different. These data will be used to assess the tsunami flow velocity. Video and water level data provide valuable and important information of tsunami propagation into river. Regarding to the previous descriptions, there is the most appropriate place as study area.

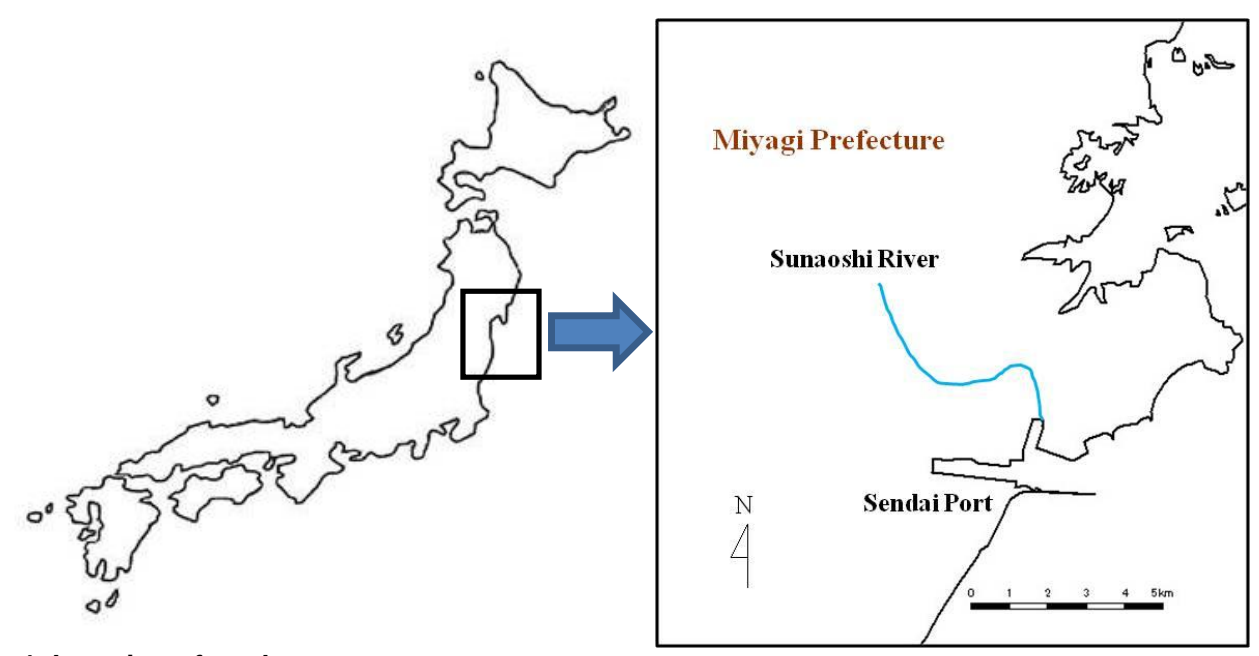

Figure 1. Location of study area 


\section{DATA COLLECTION}

There were several videos, recorded at the damaged areas due to the 2011 tsunami event. These videos may provide various information regarding physical parameters of tsunami wave. Tsunami celerity and tsunami flow velocity are considered as an important physical parameters for understanding the mechanism of tsunami propagation.

In case of tsunami celerity, it can be obtained directly from video data and field survey. Adityawan et al.(2012) presented the tsunami celerity distribution by using raw video data. They proposed the method to calculate the tsunami flow velocity. However, it was not enough for verification of flow velocity due to lack of available data collection. Thus, it should be evaluated, and it needs confirmation about the tsunami flow velocity. In general, PIV method and PTV method are widely used to measure the flow velocity from recorded video images. The method is widely used in various engineering fields. Furthermore, measurement devices and technics have been developed to further enhance PIV. It is expected that the method can be performed well in practical application.

The data information is summarized in Table 1 and Figure 2. In present paper, the focus is the estimation and verification of tsunami flow velocity by using the water level data. Tsunami celerity of last tsunami event will be presented a brief description based on the previous study result.

- Video data

This video data were taken by personal digital camera. The collected raw video is used to apply video image analysis. Before that, raw video was confirmed that this video data is suitable image for image analysis or not. The collected video data are used to apply PIV and tracking debris analysis. However, it has conventional problems such as oblique viewpoint of camera and moving camera body, image quality, etc. Especially, personal video data of Sunaoshi River gives a good comparison with theoretical analysis.

- Water level data

Fortunately, the Sunaoshi River has available water level data that observed at five water level measurement stations located along the river. It was measured every 10 minutes time interval during last tsunami event. Tsunami travel distance and arrival time were estimated from the water level data at measurement stations.

\begin{tabular}{|l|l|}
\hline \multicolumn{2}{|l|}{$\begin{array}{l}\text { Table 1. Locations of water level measurement stations } \\
\text { and video recording }\end{array}$} \\
\hline No. & Distance from river mouth $(\mathrm{km})$ \\
\hline Pt.1 & 2.9 \\
\hline Video data & 3.3 \\
\hline Pt.2 & 5.5 \\
\hline Pt.3 & 6.3 \\
\hline Pt.4 & 6.7 \\
\hline Pt.5 & 6.9 \\
\hline
\end{tabular}

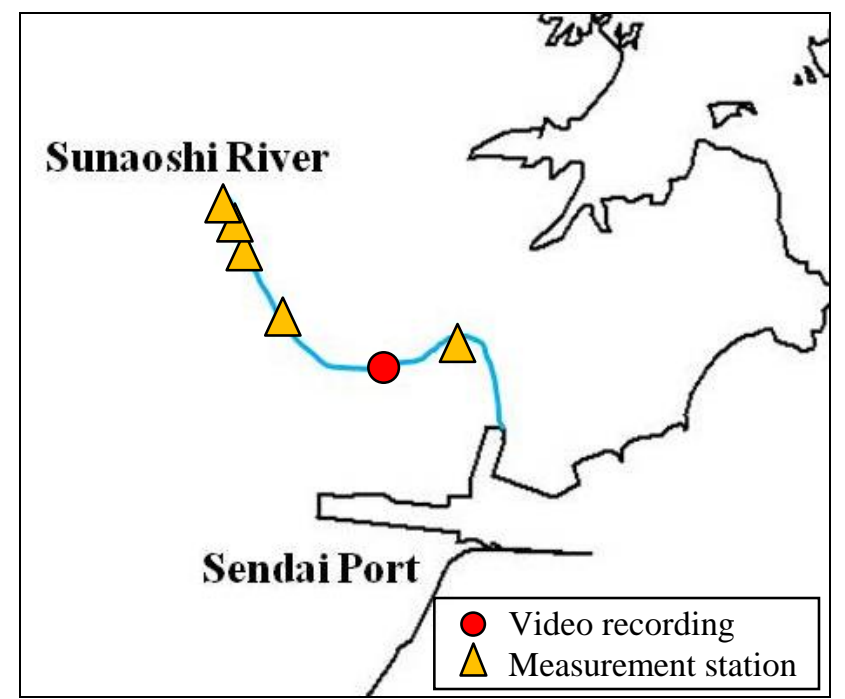

Figure 2. Video recording location and water level measurement stations of Sunaoshi River 


\section{METHODOLOGY}

1. Application of PIV and tracking debris method

Pre-processing of image stabilization and image rectification is crucial in video image analysis. These processes need to reduce analysis errors due to the camera movement and camera viewpoint. It means that the raw video data should be stabilized because it may have distortion due to oblique view and camera motion during the video recording process. Generally, a stable video may be recorded using fixed viewpoint such as tripod or other means. However, video from amateur or news are mostly recorded by hands such as the video used in this study.

In this process, each video frames were stabilized by using several fixed point such as building, structures, roads, etc. It will be analyzed and adjusted to ensure that the stable video frame remains in constant position. Figure 3-(a) shows the four fixed points for image stabilization process, and red dot area was selected for image rectification as target area. The stabilized video image does not contain any information of coordinate system to estimate displacement of image luminance. Therefore, image rectification in pre-processing is required to obtain local coordinate system to the video image. The process plays an important role in determining accurate displacement for analyzing flow velocity and direction from images. As seen in Figure 3-(b), the stabilized image was rectified to overcome the camera oblique viewpoint. The level of stabilization and rectification process has significant effect to improve accuracy of the video image analysis, whereas this process does not consider another problem such as light effect, lens distortion, etc.

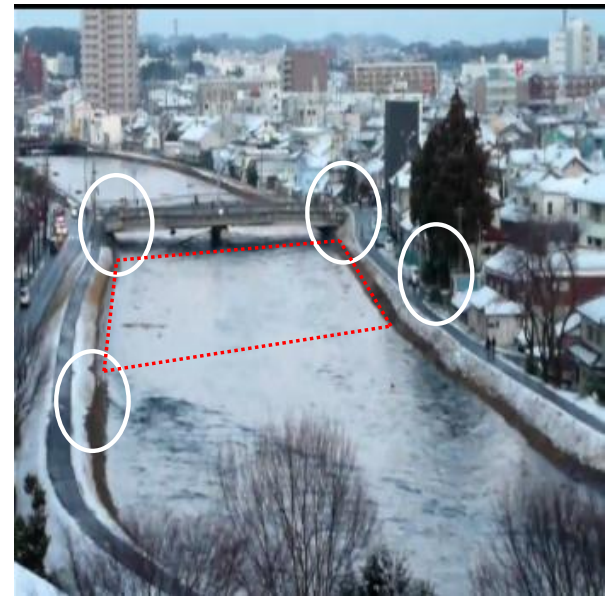

(a) Image stabilization

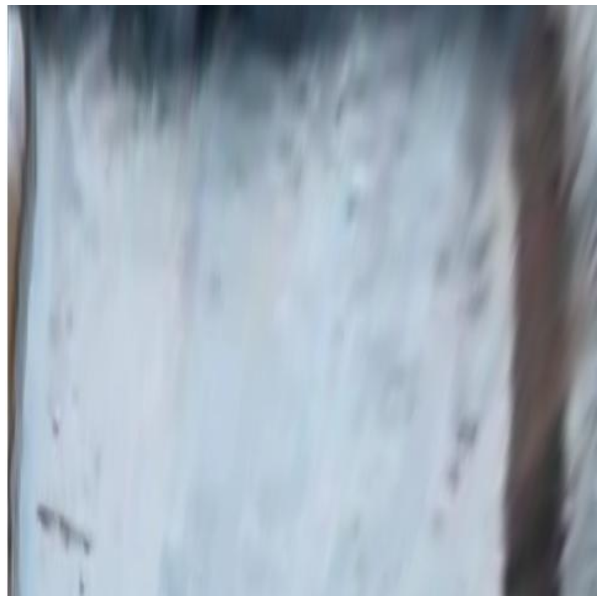

(b) Rectified image of target area

Figure 3. Image pre-processing for video image analysis

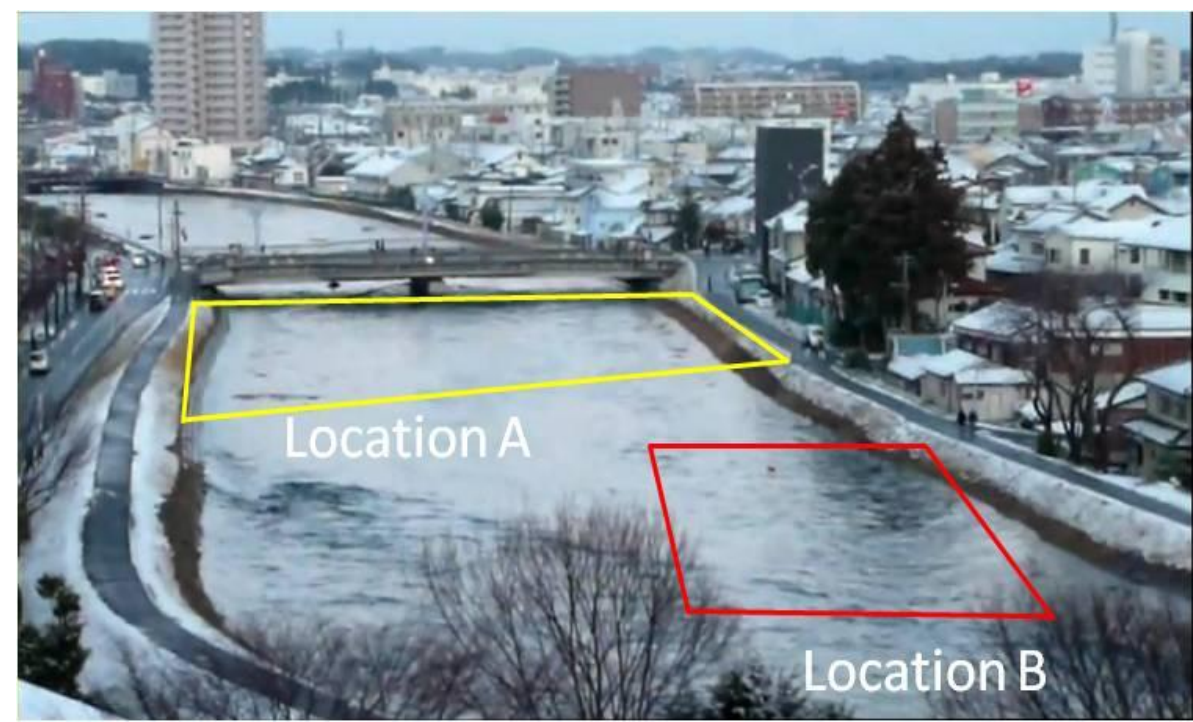

Figure 4. Analysis areas in raw video image 
The pre-processed video images were analyzed by PIV method and tracking debris method. Recently, various techniques are introduced to obtain stable and accurate result in the image analysis field. Advanced analysis method have been tried to evaluate the characteristics of flow behaviors. Muste et al. (2008) summarized the capabilities and performance of various PIV analyses. Furthermore, tracking debris method is based on Particle Tracking Velocimetry(PTV) concept that is also one method of video image analysis. In this study, tsunami debris could be found in the video data. It was assumed that the debris was regarded as water particle on the surface to assess the tsunami flow velocity.

As seen in Figure 4, Location A and Location B in the video were selected to apply PIV method and tracking debris method. Location A is river downstream area and Location B is river upstream area. PIV method was utilized on Location A, and PIV and tracking debris method was applied to Location B, respectively. Therefore, it is that flow velocity changes along the river can be observed as well as river topographical effect that Location A is covered with whole river cross-section and Location B is located in curved section and near the river embankment.

2. Verification of tsunami flow velocity for PIV and tracking debris analysis
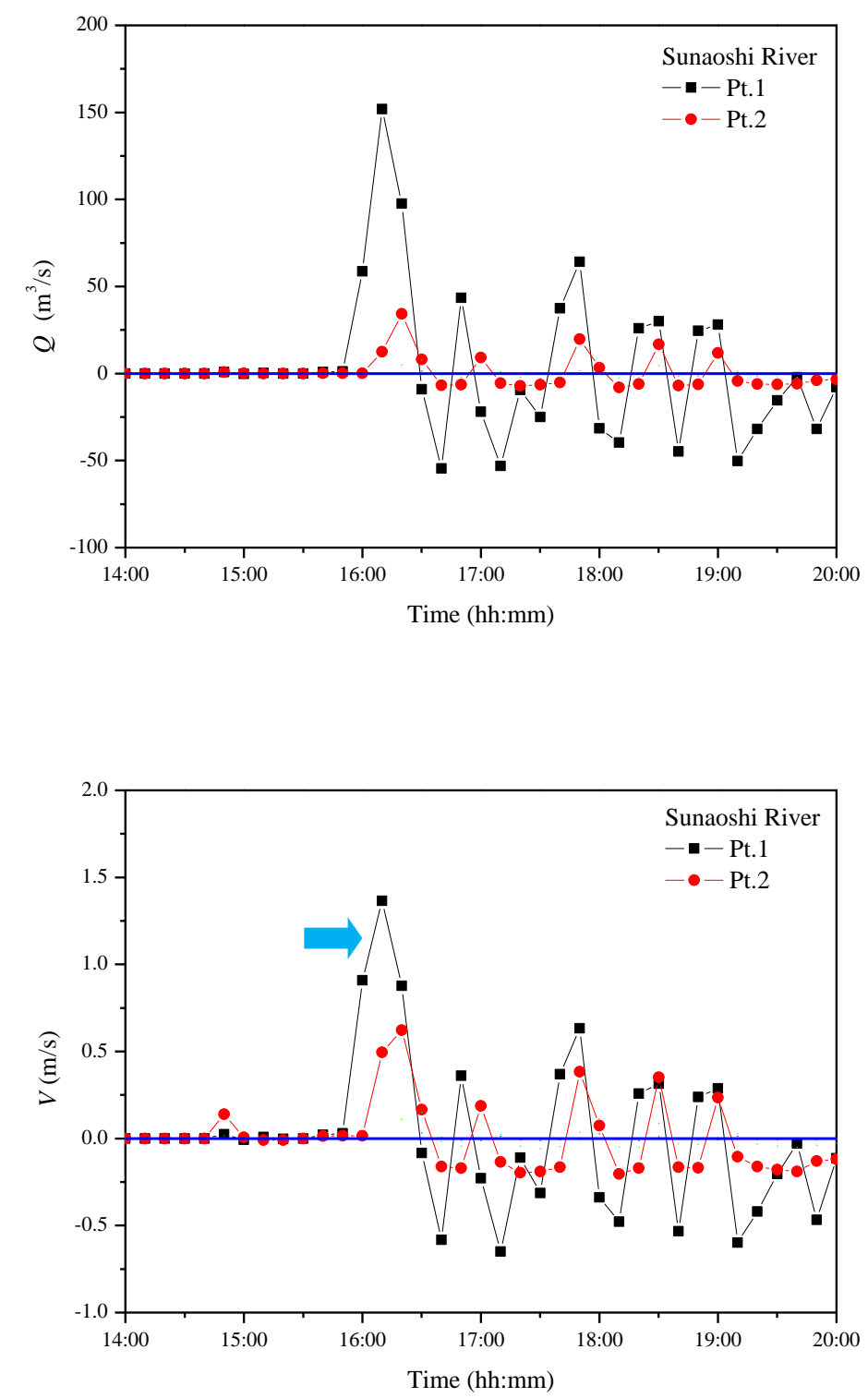

Figure 5. Calculated river discharge and flow velocity at Pt.1 and Pt.2(Adityawan et al., 2012) 
The calculation method is based on the conservation equation that is used to evaluate the video image analysis result. It was suggested by Adityawan et al.(2012), and the calculation result of tsunami flow velocity was referred to in this study. Pt.1 and Pt.2 result of Sunaoshi River are used to verify the video analysis result that is obtained from video recording location between Pt.1 and Pt.2. The calculated river discharge $(Q)$ and flow velocity $(V)$ are plotted in Figure 5. The positive value means that flow direction is from river downstream to river upstream. It can be observed that the peak velocity becomes slower in the function of distance from the river mouth. It was found that the maximum river discharge and flow velocity attained to $150 \mathrm{~m}^{3} / \mathrm{s}$ and $1.4 \mathrm{~m} / \mathrm{s}$ at the measurement station of $2.9 \mathrm{~km}$ from river mouth.

\section{ANALYSIS RESULT}

Video analysis result is presented in several parts. First part is the result of PIV method and tracking debris analysis. Second part is the comparison result between theoretical approach method and video image analysis.

\section{Application of PIV and tracking debris method}

The tsunami flow velocity can be determined by the time interval and displacements. The mean velocity at a specific zone was calculated by averaging vector fields over a $1 \mathrm{sec}$ time interval. PIV method was utilized to Location A and Location B that are composed of 225 and 100 estimation points, respectively.
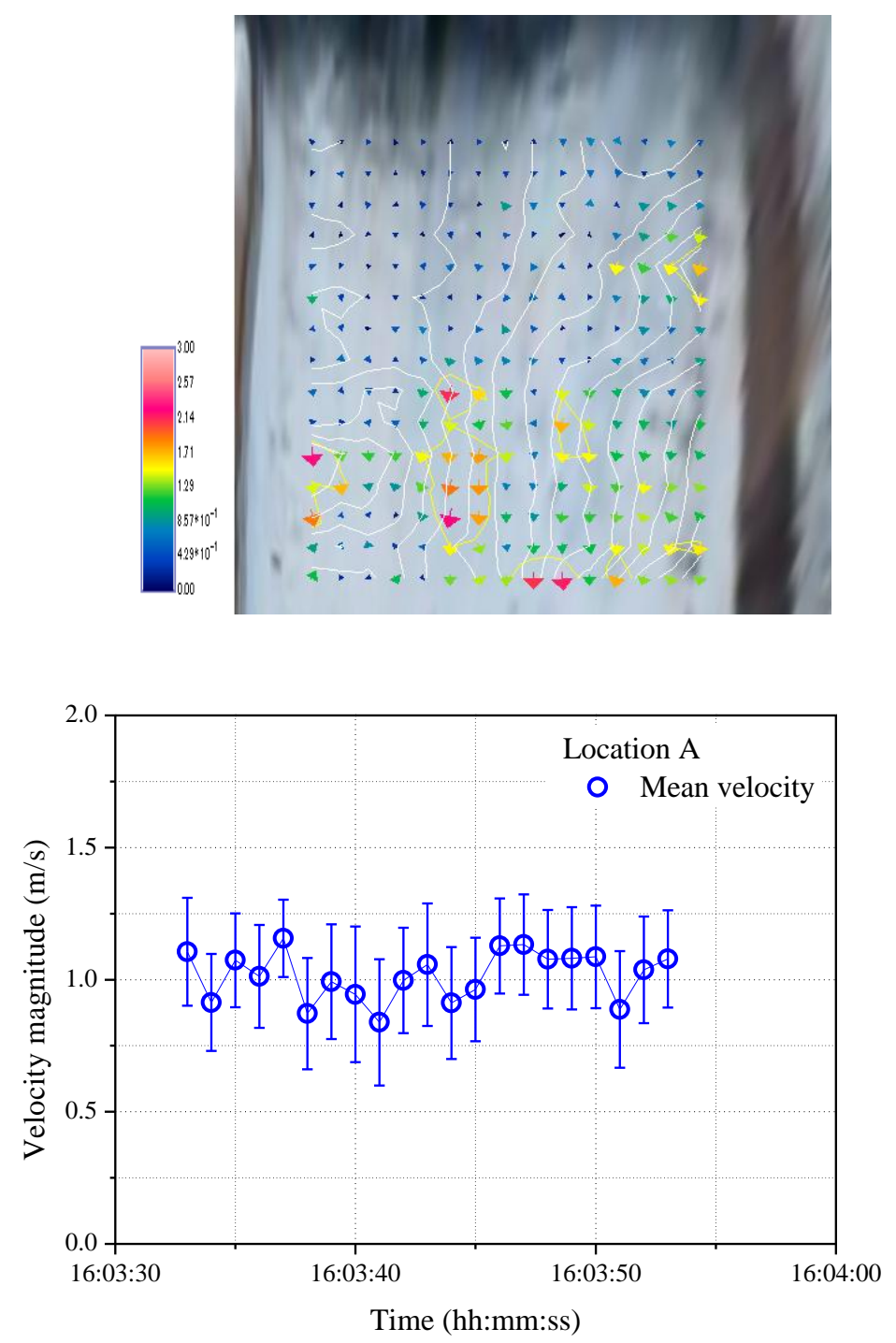

Figure 6. Estimated velocity vectors and mean velocity in Location A 


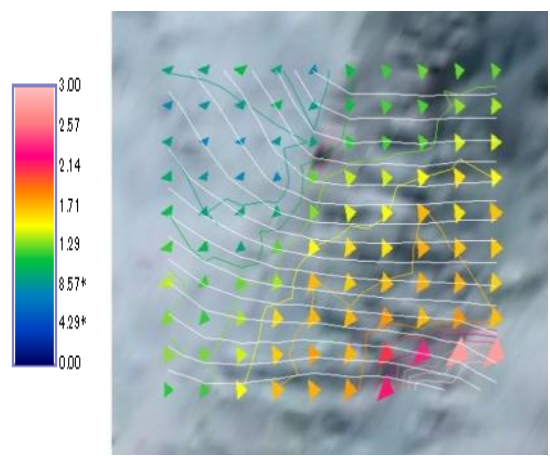

16:03:42

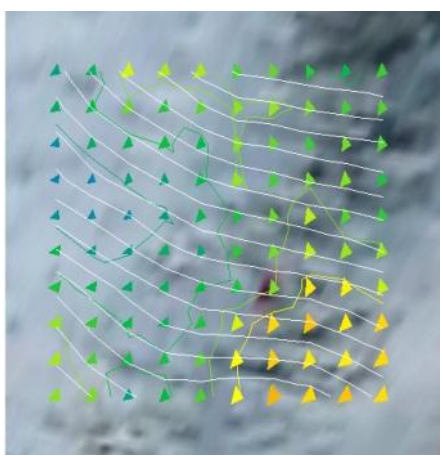

16:03:49

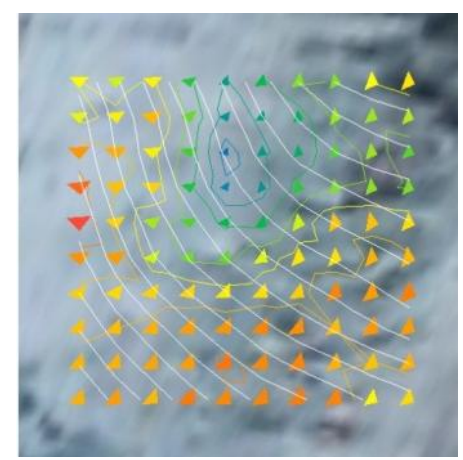

16:03:55

Figure 7. Estimated velocity vectors and mean velocity in Location A

Figure 6 shows the velocity vector at certain time and the mean flow velocity during $1 \mathrm{sec}$ in Location A. The standard deviation was used to measure the error during a $1 \mathrm{sec}$ interval in the estimation field. According to the time, the mean tsunami flow velocity including the standard deviation value is shown in this figure. The calculated mean velocity and standard deviation value of Location A. It means that various flow patterns were obtained throughout Location A by the difference of range between mean velocity and standard deviation value.

As seen in Figure 7, the change of velocity vectors of Location B is shown according to the time. There is shown the velocity vectors at three different times. Location B provides the good comparison with different image analysis method. The estimation result shows the effect of river topography. It can be confirmed by streamlines that is shown the curvature along the river channel from river downstream to river upstream.

In Figure 8, the estimated mean velocity and standard deviation value of Location B provide that smaller target area of measurement lead to reliable result compared with Location A. However, tsunami wave fluctuates every time in a real field as well as the flow velocity is changed according to the place and time. It can be obtained spurious vectors that wrong direction vectors or extremely high velocities may be released due to distorted video images in pre-processing step. It is that the accuracy of analysis method depends on the stabilization and rectification process. In this paper, the standard deviation value from the estimation result presents that the pre-processing step for image analysis is able to overcome the conventional problems of PIV method. This method can be usefully applied to many distorted video data including the conventional limitations.

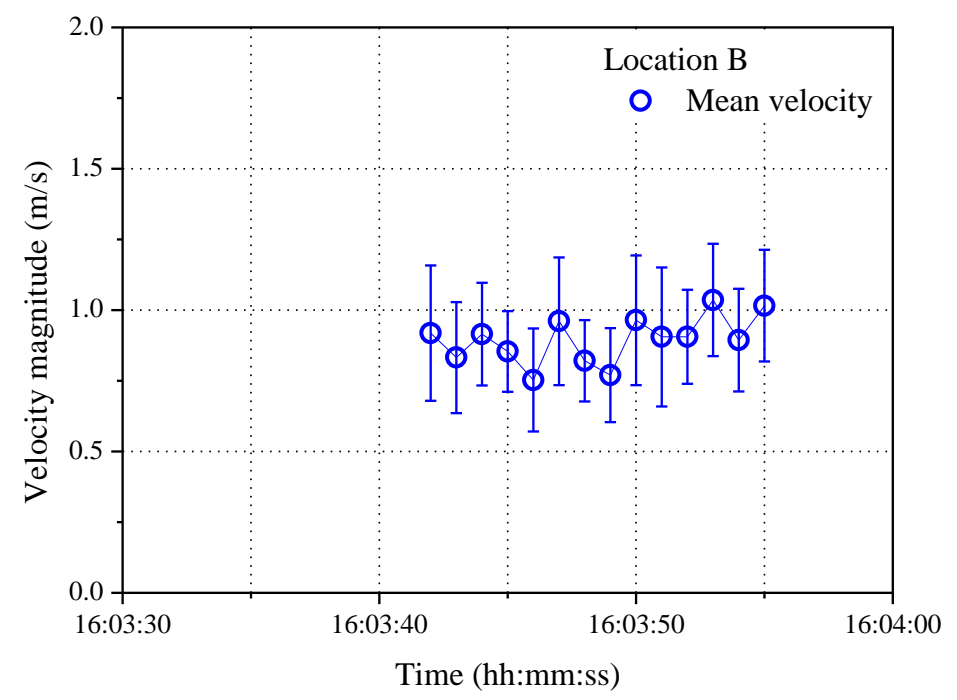

Figure 8. Estimated velocity vectors and mean velocity in Location B 

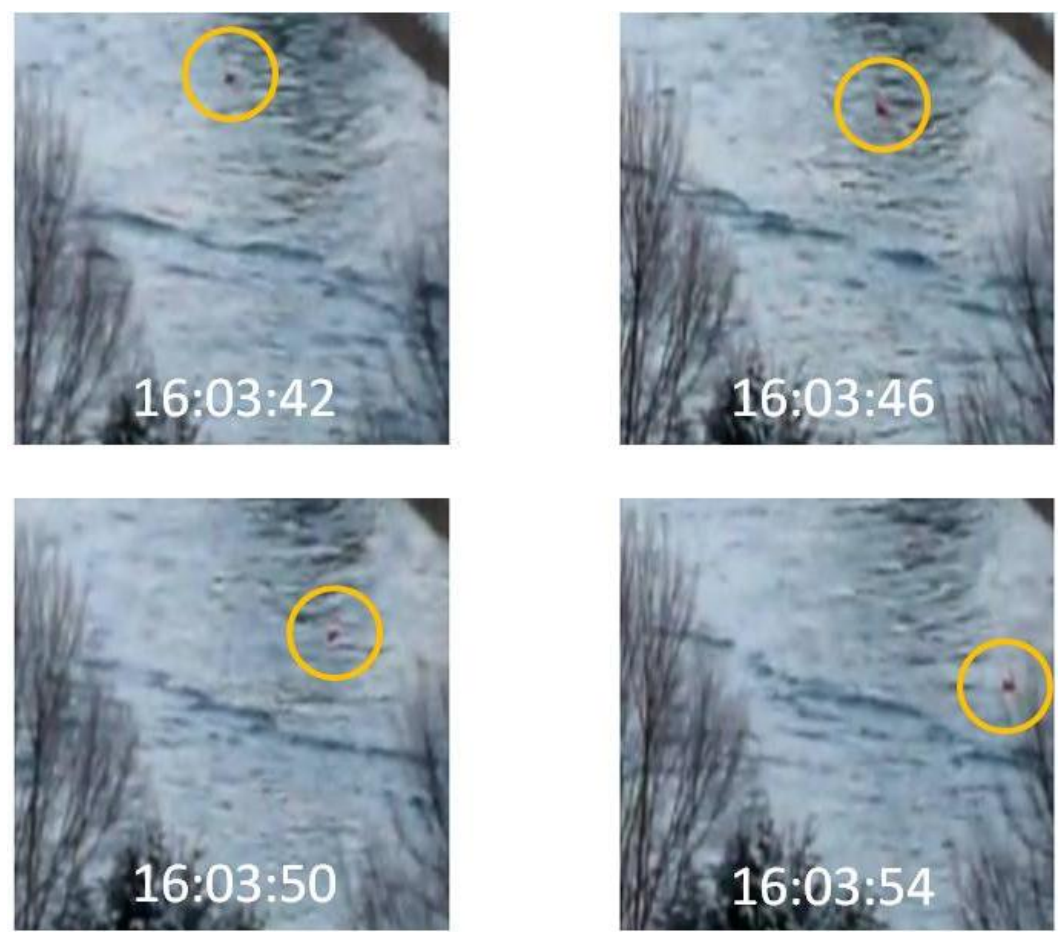

Figure 9. Movement of tsunami debris(Location B)
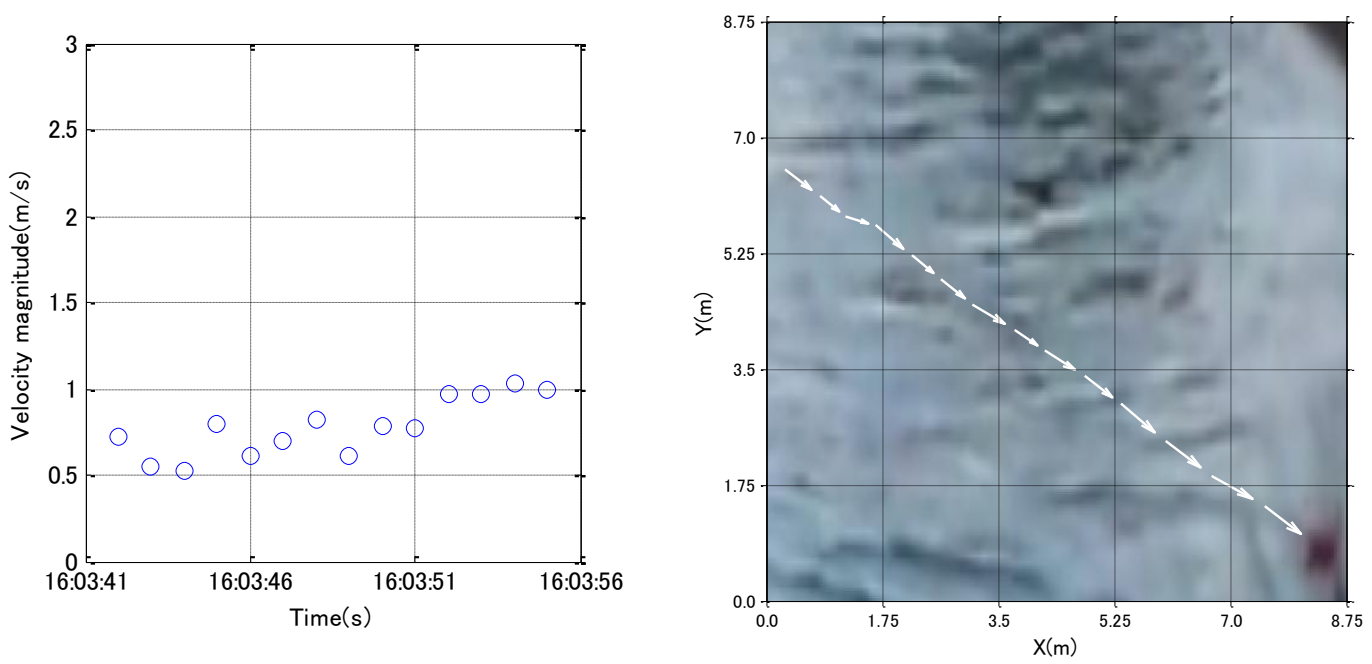

Figure 10. Velocity magnitude and vector of tsunami debris(Location B)

Tracking debris method was applied to Location B. The red object can be found floating in the raw video as shown in Figure 9. Thus, the displacement of this object can be detected. This object is chosen as the target for tracking debris analysis.

The velocity magnitude and vector of debris are shown in Figure 10. The flow velocity of debris was steadily increasing during around 15 seconds, and then the peak velocity is attained as $1.03 \mathrm{~m} / \mathrm{s}$. The direction of debris can be confirmed by vector analysis.

To verify the methods, the calculated result and image analysis results are shown in Figure 11 according to the actual time of video. The flow velocity of tsunami was estimated to be ranging from $0.6 \mathrm{~m} / \mathrm{s}$ to $1.1 \mathrm{~m} / \mathrm{s}$ by PIV and tracking debris method. Meanwhile, the calculated flow velocity was attained to the range of $1.0 \mathrm{~m} / \mathrm{s}$ to $1.2 \mathrm{~m} / \mathrm{s}$ by conservation equation at the blue arrow in Figure 5 . It was found that the estimated flow velocity of PIV method and tracking debris analysis are close to the calculated flow velocity at Pt.1 using conservation equation. 


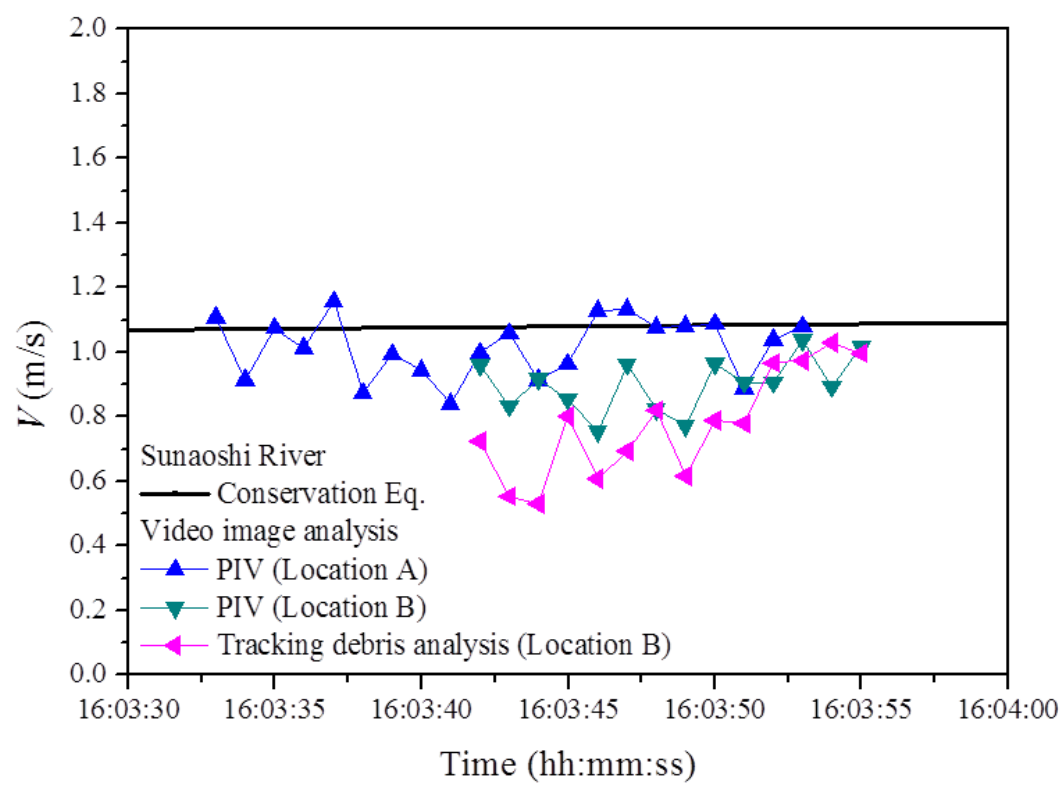

Figure 11. Comparison result of tsunami flow velocity between conservation equation and video image analyses.

The estimation results are dependable and consistent between PIV analysis, tracking debris analysis and conservation equation results although the comparison analysis was limited. The result of conservation equation was obtained from 10 minutes time interval data. On the other hand, video image analyses were conducted for a very short time data of 25 seconds. Nevertheless, it seems not only to have the similar tendency of flow velocity variation but also these methods are able to estimate the flow velocity from the distorted video images including moving camera motion and oblique viewpoint. Moreover, the effect of river topographical characteristics can be verified by using video image analysis method.

\section{CONCLUSIONS}

PIV method was applied to analyze flow velocity at Sunaoshi River due to tsunami propagation in 2011. The application of PIV method has been verified by various approaches in this paper. The PIV results were compared to the results from PTV and theoretical approach.

Overall, the results from all of the methods present similar trend and behavior. The tsunami flow velocity is obtained successfully under the limited data availability. This measurement process and analysis method can be used to overcome the conventional limitations such as moving camera motion and oblique viewpoint. Furthermore, video analysis method can be extended to other many video data to assess tsunami flow velocity. It can be used to verify the effect of various dominant parameters such as river topography and so on.

In conclusion, the proposed methods can be useful to estimate tsunami flow velocity, especially in this case that there are no adequate data and analysis condition. It is hoped that more detail analyses based on the present methods in this study may provide a better understanding for tsunami propagation mechanism.

\section{ACKNOWLEDGMENTS}

The authors would like to thank the financial supports from the Grant-in-Aid for Scientific Research from JSPS (No. 21360230, No. 22360193, No. 2301367), Grant-in-Aid for Scientific Research from the River Environmental Fund (REF) in charge of the Foundation of River and Watershed Environmental Management (FOREM), and the Collaborative Research Fund, Disaster Prevention Research Institute, Kyoto University, as well as Assistance for Technological Development, Tohoku Construction Association. The third author is a Postdoctoral Fellow granted by JSPS(No. P11367). This is where one acknowledges funding bodies, etc. 


\section{REFERENCES}

Abe, K. 1986. Tsunami propagation in rivers of the Japanese Islands, Continental Shelf Research, 5, No.6, 665-677.

Adityawan, M. B., Roh, M., Tanaka, H., Mano, A., and Udo, K. 2012. Investigation of tsunami propagation characteristics in river and on land induced by the Great East Japan Earthquake 2011, Journal of Earthquake and Tsunami. (in press)

Fritz, H. M., Borrero, J. C., Synolakis, C. E., and Yoo, J. 2006. 2004 Indian Ocean tsunami flow velocity measurements from survivor videos, Geophysical Research Letters, 33, L24605.

Fujita, I. and Kawamura, Y. 2001. Discharge measurements of flood flow by imaging technology and float method, XXIX IAHR Congress Proceedings.

Hauet, A., Creutin, J. D., and Belleudy P. 2008. Sensitivity study of large-scale particle image velocimetry measurement of river discharge using numerical simulation, J. of Hydrology, 349, 178190.

Holland, K. T., Puleo, J. A., and Kooney, T. N. 2001. Quantification of swash flows using video-based particle image velocimetry, Coastal Engineering, 44, 65-77.

Kantoush, S. A., Schleiss, A. J., Sumi, T., and Murasaki, M. 2011. LSPIV implementation for environmental flow in various laboratory and field cases, J. of Hydro-environment Re-search, 5, 263-276.

Muste, M., Fujita, I., and Hauet, A. 2008. Large-scale particle image velocimetry for measurements in riverine environ-ments, Water Resources Research, 44, W00D19.

Tanaka, H., Ishono, K., Nawarathna, B., Nakagawa, H.,Yano, S., Yasuda, H., Watanabe, Y., and Hasegawa, K. 2008. Field investigation of disasters in Sri Lankan rivers caused by The 2004 Indian Ocean Tsunami, 26, No.1, 91-112

Tanaka, H., Tinh, N. X., Roh, M., and Dao, N. X. 2011. Propagation of 2010 Chilean Tsunami into rivers in Tohoku District -tsunami intrusion and river mouth morphology-, Annual Journal of Hydraulic Engineering, 55, S1627-S1632. (in Japanese)

Tsuji, Y., Yanuma, T., Murata, I., and Fujiwara, C. 1991. Tsunami ascending in rivers as an undular bore, Natural Hazards, Vol.4, 257-266.

Wijetunge, J. J. 2009. Field measurements and numerical simulations of the 2004 tsunami impact on the south coast of Sri Lanka, Ocean Engineering, 36, 960-973.

Yasuda, H. 2010. One-dimensional study on propagation of tsunami wave in river channels, Journal of Hydraulic Engineering, ASCE, 93-105. 